\title{
Field Trip Education Approach Beyond Classroom: Microwave Course Case
}

\author{
Azhar Fauzi ${ }^{1}$ \\ Zairi Ismael Rizman²* \\ ${ }^{1}$ Politeknik Kuala Terengganu, ${ }^{2}$ Universiti Teknologi MARA (Terengganu) \\ *Email: zairi576@tganu.uitm.edu.my
}

\section{Doi:10.5901/mjss.2015.v6n4s1p89}

\section{Abstract}

\begin{abstract}
This research was conducted to identify the perception of Diploma in Electronic Engineering (DKE) students who had attended the trip to Beserah earth satellite station. The research instrument was a two-page self-administered questionnaires consisting of a dependent variable measures appropriateness of implementation and two independent variables measure benefits to individual and helpful in effective learning. The total of 103 samples only focused on the students who are studying microwave course. This study conducted a quantitative perception study in which the questionnaires were used to process the received data to produce a conclusion. Data collection of self-administered questionnaire was conducted at Beserah earth satellite station, Kuantan. Reliability analysis of the instruments was processed by using Statistical Package for the Social Sciences (SPSS). The internal consistency of the variables was estimated by the Cronbach's Alpha reliability coefficient, which above 0.7. The finding provides concrete evidence to support a field trip as an approach of microwave education relate to appropriateness of implementation. The two factors, viz., benefits to individual and helpful in effective learning are positively and significantly correlated with appropriateness of implementation. Besides, $43.4 \%$ of the factors are able to explain appropriateness of field trip implementation.
\end{abstract}

Keywords: field trip; microwave; education; SPSS; electrical engineering;

\section{Introduction}

A great emphasize of teaching and learning strategies will result the effectiveness of an educational process. The purposes of education are mainly to develop knowledge, skills and character of students (Rise, 2006). Therefore, the education is the process of learning and knowing, that is not limited to school/learning institution or textbooks. The students should nurtured and educated by a variety of teaching methods to produce quality students (Khairi, 2008). In the context of learning at Sultan Mizan Zainal Abidin Polytechnic (PSMZA), lecturers need to use appropriate methods to help students achieve the objectives of teaching and learning sessions as planned.

According to Trigwell and Prosser (2004) in the Vajoczki et al. (2011), the objective of most educators is to facilitate deep learning strategies in support of critical thinking and knowledge application, thus can increase the earnings of learning.

About microwave concept, photodiode light is absorbed on both sides of the metallurgical junction. For the wavelengths of interest, one electron-hole pair is generated for each absorbed photon. The minority carriers from these pairs either recombine or flow across the junction. The minority carriers, which cross the junction, constitute the photocurrent.

\section{Literature Review}

\subsection{Background of study}

There are many theories on teaching methods that can be used by the lecturers to maximize the delivery of knowledge in various fields (Currigan, 2009). Among the methods that can be used in teaching and learning process is the method of travel/tour, which is known as field trip education. Trip education method can be defined as an activity which allows students to observe what they have learned in real situations. As a result, students acquire the information directly and teachers can explain more efficiently on something cannot be brought into the classroom. In addition, the field trip can provide an opportunity for students to observe on a particular matter or circumstances directly outside the classroom. 
Problem may be arise to the teachers to the needs of the field trip as the availability of teaching materials that can be accessed through internet. Moreover, the field trip is inconvenient and difficult for organized and supervised (Bimstein et. al., 2008). Despite such perceptions, field trips provide learning opportunities which is not available in the classroom. Through field trips, many of the concepts and phenomena are easily explained, understood, and assimilated. With the help of field trip too, it can save energy and time for both lecturers and students. Among the important features of field trip is that students having the opportunity to experience real situations or look more closely at the latest technology to be applied (Shakil et al., 2011). It is the variation in teaching and learning process that will excite students to learn something and retain memory on the topic that has been taught (Kiyici \& Yigit, 2010).

According to Myers and Jones (2009), educational field trip has long been a major part of program of education for both youth and adults. However, due to financial factors, constraints of time and contingent liabilities, many lecturers are reluctant to supervise study tours or trips.

Microwave course is one of the elective courses for students in Diploma in Electronic Engineering (DKE) of Polytechnic of Sultan Mizan Zainal Abidin. Microwave course syllabus for a semester is composed of five main topics namely basic microwave, microwave components, microwave measurements, microwave sources and microwave antennas.

In general, the microwave can be defined as an electromagnetic wave having a very high frequency and the wavelength is very short in which the frequency band from $1 \mathrm{GHz}$ and $100 \mathrm{GHz}$. It is one type of wireless communication line in a communication systems and an alternative to fiber optic. Microwave bands are capable of producing economical transmission lines where many communication channels or broadcast television (TV) can be modulated by single microwave carrier and send all these channels via a communication link.

\subsection{Problem statement}

Microwave courses require students to have prior knowledge related to communication systems. Therefore, students need to know the communication systems terminologies in advance since microwave is the branch of communication systems engineering.

Nowadays, the technology of communication systems is expanding very quickly. As lecturers, the ability to provide information on latest communication system applications is limited as activity in the classroom/lab which focused on theory and the syllabus. Hence, the students cannot understand on how the technologies of communication and microwave systems generally work. Students also cannot imagine the actual equipment used in the systems and the linking between communication and microwave systems. This created a sense of lack of interest in microwave course.

\subsection{Purpose of study}

This study was conducted to identify perception of the field trip of DKE students who had attended the trip to Beserah earth satellite station. In addition, researcher want to know whether there were significant differences between gender and student programs for the item studied. With this, the management will be able to assess and support student activities that lead to the teaching and learning in line with the core strategic plan of the Ministry of Higher Education in improving the quality of teaching and learning. It is the hope of researcher so that students gain the exposure accordingly to communication system technology in general and self confidence to pursue employment or further education after graduate.

\subsection{Scope and focus research}

Various theories related to teaching methods can be obtained through books or articles, but the study of the effectiveness of field trip activities is rarely done by lecturers. The samples of the study are from the students of DKE who learn microwave course. Questionnaires had been given to all students who had been on the field trip.

A total of 15 instruments were built consisting of a dependent variable and two independent variables to obtain feedback from students. The instruments will focus on student exposure in communication systems in general, and microwave system particularly. 


\section{Research Methodology}

\subsection{Introduction}

This section presents the methodology of the study. It begins with research instrument. This is followed by sampling procedure and data collection method. A research design diagram was also included for better understanding.

\subsection{Instrument}

The study was a quantitative perception in which the research instrument was used to process the received data to produce a conclusion. The research instrument was a two-page self-administered questionnaire. The first section measured benefits for individual comprising of 5 questions. The second section measured the helpful in effective learning which involves 6 questions. The first and second sections are independent variables. Whereas, a dependent variables represented by appropriateness of implementation involving of 4 questions. Students were asked to indicate their level of agreement on a 6 point scale ( 1 = strongly disagree to $6=$ strongly agree). Based on the findings of the pilot test survey, some of the statements were improved (Babbie, 2013) since many respondents could not understand properly. The research design was shown in Fig. 1.

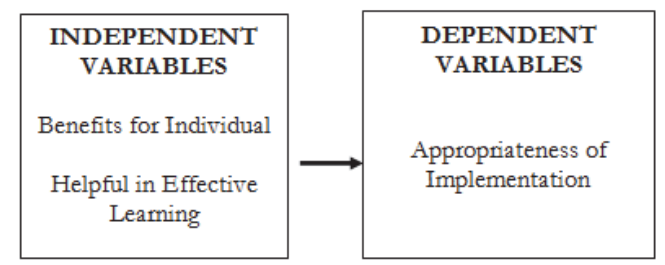

Figure 1. Basic Research Design

\subsection{Sampling procedure and data collection method}

In general, the population study consists of students of DKE which is involving in microwave class. The research instrument had been distributed to all students who had attended the field trip which involves 103 respondents. Data collection was carried out at Beserah satellite earth station, Pahang. Questionnaires had been given to participants at the earth station and returned to the lecturers on the same day.

\section{Findings and Discussion}

\subsection{Introduction}

This section presents the findings of the survey. It begins with a respondent demography. This is followed by factor analysis, reliability test, multiple regression and correlations. Finally, a comparison was made between gender and programs of the respondents.

\subsection{Characteristic of respondents}

A total of 103 responses were received and all useable for analysis. This indicates a response rate of $100 \%$. Male respondents (57.3\% of the total) are slightly higher than female respondents (42.7\%).

In terms of program, DKE6-S2 made up the largest group of respondents (29.1\%) followed by DKE6-S1 (25.2\%) and DKE6-I (23.3\%). The smallest group of respondents is represented by DKE-S3 (22.3\% of the total).

\subsection{Factor analysis and reliability test}

Factor analysis was performed on the 15 statements to identify the underlying dimensions measured by the statements. The analysis was also to determine whether the data could be summarized into smallest set of factor or dimensions. 
The principal components analysis performed, extracted three factors having eigenvalues greater than 1.0 as shown in Table 1. The three factors accounted for $52.73 \%$ of the total variance. Only items with factor loadings of 0.3 and above were considered as significant in interpreting the factors. Factor 1 was loaded with six items, explaining $23.57 \%$ of the variance, while factor 2 comprising five loaded items which explaining $18.76 \%$ of variance.

Table 1. Factor Loadings and Reliability Test for Overall Field Trip

\begin{tabular}{|lll|}
\hline Subscale & Loadings CITC Alpha Scores \\
\hline Factor 1: Benefits to Individual & \\
Participant can play proactive role in interacting directly with organization & 0.601 & 0.607 \\
Participant able to consolidate knowledge through visit that were conducted & 0.585 & 0.624 \\
Participant gets value added to the courses studied & 0.509 & 0.596 \\
Trip destination is suitable to the courses studied & 0.692 & 0.610 \\
This program can increase understanding of communication engineering technology in general & 0.604 & 0.673 \\
This program will create a learning culture among students & 0.521 & 0.535 \\
Factor 2: Helpful in Effective Learning & \\
Participant gains exposure to the real situation in microwave system equipments & 0.620 \\
Participant gets a clear picture of microwave system components that have been taught in classroom & 0.603 \\
Participant can relate the trip experience with teaching and learning process in classroom & 0.802 & 0.716 \\
Participant gains exposure to careers in the scope of communication systems in general & 0.491 & 0.577 \\
This program can increase understanding of microwave technology particularly & 0.603 & 0.550 \\
Appropriateness of Implementation & 0.598 & 0.600 \\
The program has been implemented smoothly & \\
The period provided for the trip is appropriate & 0.595 & 0.685 \\
This program is beneficial to students & 0.756 & 0.515 \\
This program is suitable implemented to students in future & 0.331 & 0.528 \\
\hline
\end{tabular}

The corresponding items are positively and substantially loaded on benefits to individual, helpful in effective learning and appropriateness of implementation. The item 'trip destination is suitable to the courses studied', had the highest factor loading in factor 1. The item 'participant obtains a clear view of microwave system components that have been taught in classroom' had the highest factor in factor 2. The highest factor loading item in the dependant variable was 'the period provided for the trip is appropriate'.

Reliability analysis had been conducted for the rest of the 15 items, and all items showed more than 0.3 corrected item-total correlation (CITC). Therefore, all items in the three subscales can be considered acceptable. The internal consistency of the three subscales was estimated by the Cronbach's Alpha reliability coefficient (Wiersme \& Jurs, 2009; Wang \& Carlson, 2011). Table 1 shows the alphas were all well above 0.7. The items measuring appropriateness of implementation displayed acceptable $(\alpha=0.749$ ). However, both factors are considered good (Benefits to individual, $\alpha=$ 0.834; Helpful in effective learning, $\alpha=0.814$ ) (Sekaran \& Bougie, 2010).

\subsection{Multiple regression and correlations}

A multiple regression was conducted to identify the relationship between appropriateness of implementation and the two factors or predictors. Table 2 summarized the statistics and the analysis results. The result showed all the factors are positively and significantly correlated with appropriateness of implementation. Pearson correlation values in between 0.5 to 0.69 for both factors can be considered as high correlation (De Vaus, 1985). Based on standardized coefficient, the most contributing factor is benefits to individual $(\beta=0.594, p=0.000)$. Helpful in effective learning $(\beta=0.103, p=0.370)$ indicates less important predictor and it is not significant to predict appropriateness of field trip implementation. However, the value of adjusted $\mathrm{R}$ square shows 0.434 which means that $43.4 \%$ of the selected variables (both factors) are able to predict or explain appropriateness of field trip implementation.

Table 2. The Relationship between Appropriateness of Implementation with Benefits to Individual and Helpful in Effective Learning

\begin{tabular}{|lcccc|}
\hline Variable & Correlation with Appropriateness of Implementation & $b$ & $\beta$ & Adjusted R Square \\
\hline Benefits to Individual & $0.663^{*}$ & $0.630^{*}$ & 0.594 & \multirow{2}{*}{0.434} \\
Helpful in Effective & $0.501^{*}$ & 0.091 & 0.103 & \\
Learning & & & \\
\hline
\end{tabular}




\subsection{Student perceptions on field trip between gender}

Normality of the data of the field trip was explored through normality test. In reviewing the descriptive statistics and other output such as stem-and-leaf plots and box plots, it is clear that there is a minimal violation to the assumption of normality (Coakes et al., 2005). An analysis of the field trip was carried out by comparing the mean values of the two groups along the dependent variable and two independent variables. The independent group's t-test was used by examining the results of the two-tailed significance test. If $p<0.05$, it means that there is a significance difference between the means of the two independent groups.

Table 3. Comparison of Field Trip Mean Scores between Genders

\begin{tabular}{|lccc|}
\hline Variable & Men & Female & Level of Significance, $p$ using t-test \\
\hline Appropriateness of Implementation & 5.47 & 5.46 & 0.968 \\
Benefits to Individual & 5.43 & 5.33 & 0.353 \\
Helpful in Effective Learning & 5.27 & 5.10 & 0.143 \\
\hline
\end{tabular}

According to Table 3, the mean difference for appropriateness of implementation between male is only 0.01 higher than female. Whereas the two independent variables, viz., benefits to individual and helpful in effective learning indicated that mean for male is slightly greater than female. From the level of significance results, it can be concluded that there was not a significant difference between genders with regards to all variables.

\subsection{Students perceptions on field trip between programs}

As indicated in Table 4, the number of sub-samples was not enough to analyze one way analysis of variance (ANOVA). The sample required for each group should be at least minimum of 30 . As an alternative, Kruskal-Wallis $\mathrm{H}$ test was used where normality of distributions cannot be assumed (Sekaran, 2003).

Table 4. Comparison of Field Trip Mean Scores between Programs

\begin{tabular}{|lllc|}
\hline Variable & Program & Mean & Level of Significance, p \\
\hline \multirow{4}{*}{ Appropriateness of Implementation } & DKE6-S1 & 5.51 & \\
& DKE6-S2 & 5.51 & 0.079 \\
& DKE6-S3 & 5.26 & \\
Benefits to Individual & DKE6-I & 5.57 & \\
& DKE6-S1 & 5.40 & \\
& DKE6-S2 & 5.39 & 0.011 \\
Helpful in Effective Learning & DKE6-S3 & 5.17 & \\
& DKE6-I & 5.59 & \\
& DKE6-S1 & 5.10 & 0.02 \\
& DKE6-S2 & 5.15 & \\
& DKE6-S3 & 4.99 & \\
& DKE6-I & 5.57 & \\
\hline
\end{tabular}

The mean scores among programs show the range of 5.26 to 5.57 for appropriateness of implementation variable. From the result of significance test, the level of significance for appropriateness of implementation indicated that $p=0.079$ and $p>0.05$. Therefore, there was no significant difference between students among programs pertaining to implementation effectiveness. However, when dealing with benefits to individual and helpful in effective learning, the mean scores for DKE6-I indicated 5.59 and 5.57 respectively. The values were quite high compared to the other three programs. This coincided with the significance value for benefits to individual $(p=0.01, p<0.05)$ and helpful in effective learning $(p=$ $0.02, p<0.05)$. On the other hand, there were significant differences among programs regarding benefits to individual and helpful in effective learning.

\section{Concluding Remarks and Recommendations}

This study is among of many researches to investigate at differentiation between gender and students programs angle. 
Though it can be considered a perception study and the samples are limited in PSMZA, the findings are quite useful for other researcher to further explore. However, the findings are not for generalization but for this sample only.

The finding provides concrete evidence to support a field trip as an approach of microwave education relate to appropriateness of implementation. The two factors, viz., benefits to individual and helpful in effective learning are positively and significantly correlated with appropriateness of implementation. Besides, $43.4 \%$ of the factors are able to explain appropriateness of field trip implementation and, there some other factors (56.6\%) could be found in other researches.

Majority of the respondents stated that the field trip really benefited to them, helped in effective learning and the implementation was done appropriately. In conclusion, there is no significant difference between male and female with regards to all variables.

There are indeed some significant differences between student program with respect to benefits to individual and helpful in effective learning. However, there was no significant difference between students among program pertaining to appropriateness of implementation.

The transformation of polytechnics, consisting of four cores in which one of them is empowering with knowledge and highly competent must be implemented with the cooperation of all parties in PSMZA. This study has shown the field trip get positive responses from students. However, emphasizing on activities during the tour should be done more effectively to increase learning interests and transfer the field trip experience into a meaningful learning experience. To conduct an effective field trip, the management should provide adequate funds and resources for coordination at all levels. Every student has a specific character and quality. With the help of field trip, it will improve leadership, selfconfidence and broadening the knowledge aspects. With the help and involvement of all parties to equip students with a variety of teaching methods including field trip, researcher believes that employability skills among PSMZA students are going increased.

\section{References}

Babbie, E. (2013). The basics of social research. (6th ed.). California: Cengage Learning.

Bimstein, E., Gardner, Q. W., Riley, J. L., \& Gibson, R. W. (2008). Educational, personal, and cultural attributes of dental students' humanitatian trips to Latin America. Journal of Dental Education, 72, 1493-1509.

Coakes, S. J., Steed, L., \& Dzidic, P. (2006). SPSS: Analysis without anguish using SPSS version 12.0 for windows. (1st ed.). New York: John Wiley \& Sons.

Currigan, S., (2009), Constructive ideas for teaching addition skills. [Online] Available: http://www.edarticle.com./articles/720/ constructive-ideas-for-teaching-addition-skills.php (July 13, 2009)

De Vaus, D. A. (2002). Surveys in social research. (5th ed.). New Soth Wales: Allen \& Unwin.

Khairi, M., (2008), Management of teaching and learning. [Online] Available: http://www.freewebs.com/ptk2.ptkkhusus2.htm (March 11, 2015)

Kiyici, F. B., \& Yigit, E. A. (2010). Science education beyond the classroom. International Online Journal of Educational Sciences, 2(1), 225-243.

Myers, Brian, \& Jones, Linda, (2009), Effective use of field trips in educational programming: A three stage approach. [Online] Available: http://edis.ifas.ufl.edu/pdffiles/WC/WC05400.pdf (March 11, 2015)

Rise, G., (2006), Adult learning theory. [Online] Available: http://www.edarticle.com./articles/203/adult-learning-theory.php (October 10, 1999)

Sekaran, U. (2003). Research methods for business: A skill building approach. (4th ed.). New York: John Wiley \& Sons.

Sekaran, U., \& Bougie, R. (2010). Research methods for business: A skill building approach. (6th ed.). New York: John Wiley \& Sons.

Shakil, A. F., Faizi, W. U. N., \& Hafeez, S. (2011). The need and important of field trips at higher level in Karachi, Pakistan. International Journal of Academic Research in Business and Social Sciences, 2, 1-16.

Trigwell, K. \& Prosser. M. (2004). Development and use of the approaches to teaching inventory, Educational Psychology Review, 16(4), 409-424.

Vajoczki, S., Watt, S., \& Vine, M. M. (2011). Inquiry learning: instructor perspectives. The Canadian Journal for the Scholarship of Teaching and Learning, 2, 1-18.

Wang, H. H., \& Carlson, S. P. (2011). Factors that influence student's satisfaction in an environmental field day experience. International Electronic Journal of Environmental Education, 1, 131-137.

Wiersme, W. \& Jurs, S. G. (2009). Research methods in education: An introduction. (9th ed.). Massachusetts: Pearson. 